\title{
UN MARCADOR MOLECULAR PARA EL DIAGNÓSTICO DEL OJO SECO
}

\section{A MOLECULAR MARKER FOR DRY EYE}

\author{
PINTOR J ${ }^{1}$
}

En el año 1989 comencé a realizar mi tesis doctoral en departamento de Bioquímica y Biología Molecular IV de la facultad de veterinaria de la Universidad Complutense de Madrid. Mi trabajo versó sobre un tipo de moléculas denominadas diadenosin polifosfatos, que parecían interesantes porque en el sistema nervioso central se comportaban como neurotransmisores (1). Estas moléculas, aunque poco conocidas, parecen intervenir en un número importante de procesos biológicos. Desde el punto de vista molecular, los diadenosin polifosfatos son compuestos que están formados por dos adenosinas unidas entre si por una cadena de fosfatos. A estas biomoléculas se les suele denominar de forma abreviada como ApnA donde «n» es el numero de fosfatos que puentea ambas adenosinas.

Cuando por avatares de la vida comencé a trabajar en la Escuela Universitaria de Óptica de la Universidad Complutense de Madrid comencé a valorar la posibilidad de investigar el papel de estas moléculas en el ojo. Comenzando por el papel de estas sustancias en el control de la presión intraocular y su presencia como componentes naturales del humor acuoso, los resultados pronto apuntaron a que algunas de estas sustancias podían ser reguladores naturales de la presión intraocular (2). Sin embargo pese a que este aspecto es sin duda relevante, uno de los aspectos más sorprendentes de la importancia de los diadenosin polifosfatos en el ojo ha sido su papel en la superficie ocular.

En primer lugar ha resultado grato comprobar que tanto en los modelos animales como en la lágrima humana, los diadenosin polifosfatos, en particular $\mathrm{Ap}_{3} \mathrm{~A}$ y $\mathrm{Ap}_{4} \mathrm{~A}$, son componentes intrínsecos de la misma (3). Se ha podido observar que las lesio- nes superficiales producidas por un cuerpo extraño, cicatrizan con más rapidez cuando está presente el $\mathrm{Ap}_{4} \mathrm{~A}$, puesto que este compuesto acelera la migración de las células epiteliales de la córnea cerrando rápidamente las heridas corneales (4). Este nuevo aspecto es muy atractivo porque podría pensarse en emplear estas moléculas para facilitar la cicatrización tras una operación de cirugía refractiva.

Un tema candente cuando hablamos de la superficie ocular es sin duda alguna el ojo seco. Siempre complejo y controvertido, dada su diversa etiología y su dificil diagnóstico dada la escasa correlación entre los signos y los síntomas, esta patología advertida por tanta gente no goza de un tratamiento eficaz, entre otras cosas por las dificultades que existen en su diagnóstico (5-7).

Recientemente los estudios realizados en numerosos pacientes con ojo seco han demostrado que existen variaciones significativas en las concentraciones de $\mathrm{Ap}_{4} \mathrm{~A}$ tanto si los pacientes presentan lagrimación normal como si son de lagrimación baja. En ambos casos, la concentración de $\mathrm{Ap}_{4} \mathrm{~A}$ se encuentran muy incrementada. Dicho con otras palabras, los niveles de esta sustancia varían independientemente de la etiología del ojo seco. Tanto es así, que los niveles de $\mathrm{Ap}_{4} \mathrm{~A}$ normales se ven incrementados en los individuos con ojo seco y lagrimación normal hasta 5 veces por encima de los valores normales. Este incremento es todavía mayor cuando hablamos de individuos con ojo seco en los que su producción lagrimal es baja. En estos casos los niveles del $\mathrm{Ap}_{4} \mathrm{~A}$ están incrementados más de 100 veces (8).

La presencia acrecentada de este dinucleótido en la lágrima responde a un proceso sorprendente. El

\footnotetext{
${ }^{1}$ Doctor en Biología. Académico de la Real Academia Nacional de Farmacia. Dep. Bioquímica E.U. Óptica Universidad Complutense de Madrid. España.

E-mail: jpintor@vet.ucm.es
} 
$\mathrm{Ap}_{4} \mathrm{~A}$ se libera a la lágrima desde la superficie ocular, cornea y conjuntiva, como consecuencia del masaje que el parpado realiza sobre el ojo. En contra de lo que sería más esperable, que el $\mathrm{Ap}_{4} \mathrm{~A}$ se liberara con la lágrima desde la glándula lagrimal principal, o de las terminales nerviosas que inervan la cornea (como sucede en el sistema nervioso central), todos los estudios indican que la liberación no depende de ninguno de estos dos aspectos sino que depende directamente del grado de disconfort del paciente, que al sentir sensación de incomodidad parpadea con más frecuencia de manera involuntaria (9), liberando más cantidades de esta molécula (8).

En la actualidad, la dificultad en el diagnóstico del ojo seco no permite realizar un abordaje fiable de su tratamiento, lo que se pone de manifiesto cuando se observa la carencia de principios activos para solventar esta patología (10). Productos en base a la ciclosporina, afrontando el ojo seco como un proceso inflamatorio, o la tan deseada Prolacria (diquafosol al 2\%), que tan buenos resultados ha dado en los ensayos clínicos y que pronto estará en el mercado, conjuntamente con las lagrimas artificiales, son de las pocas alternativas de tratamiento de las que disponemos en la actualidad.

La medida de los niveles del $\mathrm{Ap}_{4} \mathrm{~A}$ en la lágrima es un método objetivo que permite diagnosticar el ojo seco de una manera fiable. Confiamos que del mismo modo que la detección de esta molécula pueda contribuir a una mejor calidad de vida de los pacientes, al poder recibir una atención más específica por parte del profesional de la visión, también esta molécula pueda ayudar a las farmacéuticas a descubrir nuevos fármacos con eficacia para el tratamiento del ojo seco.

\section{BIBLIOGRAFÍA}

1. Rodriguez del Castillo A, Torres M, Delicado EG, MirasPortugal MT. Subcellular distribution studies of diadenosine polyphosphates--Ap4A and Ap5A--in bovine adrenal medulla: presence in chromaffin granules. $J$ Neurochem 1988; 51: 1696-1703.

2. Pintor J, Peral A, Pelaez T, Martin S, Hoyle CH. Presence of diadenosine polyphosphates in the aqueous humor: their effect on intraocular pressure. J Pharmacol Exp Ther 2003; 304: 342-348.

3. Pintor J, Carracedo G, Alonso MC, Bautista A, Peral A. Presence of diadenosine polyphosphates in human tears. Pflugers Arch 2002; 443: 432-436.

4. Mediero A, Peral A, Pintor J. Dual roles of diadenosine polyphosphates in corneal epithelial cell migration. Invest Ophthalmol Vis Sci 2006; 47: 4500-4506.

5. McCarty CA, Bansal AK, Livingston PM, Stanislavsky YL, Taylor HR. The epidemiology of dry eye in Melbourne, Australia. Ophthalmology 1998; 105: 1114-1119.

6. Schein OD, Tielsch JM, Munoz B, Bandeen-Roche K, West S. Relation between signs and symptoms of dry eye in the elderly. A population-based perspective. Ophthalmology 1997; 104: 1395-1401.

7. Lemp MA. Epidemiology and classification of dry eye. Adv Exp Med Biol 1998; 438: 791-803.

8. Peral A, Carracedo G, Acosta MC, Gallar J, Pintor J. Increased levels of diadenosine polyphosphates in dry eye. Invest Ophthalmol Vis Sci 2006; 47: 4053-4058.

9. Tsubota K, Hata S, Okusawa Y, Egami F, Ohtsuki T, Nakamori K. Quantitative videographic analysis of blinking in normal subjects and patients with dry eye. Arch Ophthalmol 1996; 114: 715-720.

10. Nichols KK, Nichols JJ, Mitchell GL. The lack of association between signs and symptoms in patients with dry eye disease. Cornea 2004; 23: 762-770. 